\title{
Inhibition of the G9a/GLP histone methyltransferase complex modulates anxiety-related behavior in mice
}

\author{
Dong-yao WANG ${ }^{1,2}$, Joel KOSOWAN ${ }^{1,2}$, James SAMSOM ${ }^{1,2}$, Laura LEUNG ${ }^{2}$, Kai-lai ZHANG ${ }^{2,3}$, Ying-xiang LI ${ }^{2}$, Yan XIONG ${ }^{4}$, \\ Jian $\mathrm{JIN}^{4}$, Arturas PETRONIS ${ }^{1,2,5}$, Gabriel $\mathrm{OH}^{2}$, Albert H C WONG ${ }^{1,2, *}$ \\ ${ }^{1}$ Department of Pharmacology and Toxicology, University of Toronto, Toronto, Ontario, Canada; ${ }^{2}$ Campbell Family Mental Health \\ Research Institute, Centre for Addiction and Mental Health, Toronto, Ontario, Canada; ${ }^{3}$ Department of Health Sciences, McMaster \\ University, Hamilton, Ontario, Canada; ${ }^{4}$ Departments of Pharmacological Sciences and Oncological Sciences, Icahn School of Medicine \\ at Mount Sinai, New York, NY, USA; ${ }^{5}$ Institute of Biotechnology, Vilnius University, Vilnius, Lithuania
}

\begin{abstract}
Epigenetic gene-regulation abnormalities have been implicated in various neuropsychiatric disorders including schizophrenia and depression, as well as in the regulation of mood and anxiety. In addition, epigenetic mechanisms are involved in the actions of psychiatric drugs. Current anxiolytic drugs have significant shortcomings, and development of new medications is warranted. Two proteins, G9a (also known as EHMT2 or KMT1C) and GLP (G9a-like protein, also known as EHMT1 or KMT1D), which methylate lysine 9 of histone H3 (H3K9), could be promising anxiolytic targets. Postnatal genetic knock-out of G9a reduces anxiety-related behavior, consistent with the reduction of G9a levels by some medications used to treat anxiety (amitriptyline, imipramine and paroxetine). Conversely, there is increased anxiety-like behavior in mice with GLP haplodeficiency. We sought to determine whether two pharmacological inhibitors of G9a/GLP, UNC0642 and A-366, would have similar effects to genetic G9a/GLP insufficiency. We found that G9a/GLP inhibition with either compound reduced anxiety-like behaviors when administered to adult mice, in conjunction with decreased H3K9 methylation in the brain. In contrast, exposure to these compounds from embryonic day 9.5 (E9.5) until birth increased anxiety-like behaviors and decreased social interaction in adulthood, while H3K9 methylation was at normal levels in the brains of the adult mice. These findings reinforce genetic evidence that G9a/GLP has different effects on anxiety-like behavior at different stages of brain development, and suggest that targeting this histone methyltransferase pathway could be useful for developing new anxiolytic drugs. These data also suggest that antidepressant exposure in utero could have negative effects in adulthood, and further investigation of these effects is warranted.
\end{abstract}

Keywords: anxiety; depression; A-366; UNC0642; G9a/GLP; histone methyltransferase; epigenetics

Acta Pharmacologica Sinica (2018) 39: 866-874; doi: 10.1038/aps.2017.190; published online 8 Feb 2018

\section{Introduction}

Anxiety disorders are the most prevalent category of psychiatric conditions, with $15 \%-20 \%$ of the population meeting diagnostic criteria during their lifetime ${ }^{[1]}$. Anxiety disorders are one of the leading causes of disability in developed countries $^{[2]}$. The most effective short-term pharmacological treatments for relieving anxiety are benzodiazepines, but they have major side effects, including addiction, withdrawal, and rebound anxiety ${ }^{[3]}$. Antidepressant medications can also be used for relief of anxiety but are only partially effective. For example, in generalized anxiety disorder, only $20 \%$ of patients

\footnotetext{
${ }^{*}$ To whom correspondence should be addressed.

E-mail albert.wong@utoronto.ca

Received 2017-08-06 Accepted 2017-11-26
}

benefit from antidepressant treatment, while in post-traumatic stress disorder, $40 \%$ of patients do not respond to medication treatment ${ }^{[4,5]}$. Thus, there is an unmet need for better pharmacological treatments for anxiety.

Epigenetic gene-regulation abnormalities have been implicated in various neuropsychiatric disorders including schizophrenia and depression ${ }^{[6]}$, as well as in the regulation of mood and anxiety ${ }^{[7]}$. Epigenetic mechanisms can also mediate the effect of childhood abuse on susceptibility to psychological trauma and suicide in adulthood ${ }^{[8,9]}$. In addition, epigenetic mechanisms are involved in the actions of psychiatric drugs. The mood stabilizer valproic acid, which improves cognitive function in animal models of dementia ${ }^{[10-12]}$, is a histone deacetylase inhibitor. The antipsychotics risperidone and clozapine target the histone deacetylase HDAC2 ${ }^{[13]}$. The anti- 
depressant imipramine downregulates HDAC5, leading to increased histone acetylation at the $B d n f$ promoter and higher levels of BDNF ${ }^{[14,15]}$. Conversely, targeted histone deacetylase inhibition can have antidepressant effects ${ }^{[16]}$. Electroconvulsive therapy, which is the most effective treatment for depression $^{[17]}$, also inhibits histone deacetylases ${ }^{[18]}$. The tricyclic antidepressants amitriptyline and imipramine, along with the selective serotonin reuptake inhibitor paroxetine, inhibit DNA methyltransferase 1 (DNMT1) activity by decreasing levels of G9a, which is a known stimulator of DNMT1 $1^{[19]}$.

There is evidence that the histone methyltransferases G9a (also known as EHMT2 or KMT1C) and G9a-like protein (GLP, also known as euchromatic histone-lysine N-methyltransferase 1 or EHMT1) can modulate anxiety. These proteins form a complex that mono- and dimethylates histone 3 lysine 9 (H3K9) ${ }^{[20]}$. Mice with postnatal conditional knockout of G9a/GLP in the forebrain have decreased exploratory and anxiety-like behaviors, as well as altered social behavior ${ }^{[21]}$. In humans, the deletion or mutation of one copy of the GLP gene is sufficient to impair social behavior in the form of Kleefstra syndrome, which is characterized by mental retardation, autistic-like behavior, aggression, impulsivity, and sleep disturbances $^{[22]}$. Thus, G9a or GLP genetic knockdown at different times in development results in opposite effects on anxietylike behavior.

To further investigate this timing effect of G9a/GLP insufficiency on anxiety-related behavior, we used a pharmacological approach that is complementary to the genetic studies cited above. Two small organic molecules, UNC0642 ${ }^{[23]}$ and A-366 ${ }^{[24]}$ (Figure 1) inhibit G9a/GLP with 100-fold selectivity over other histone methyltransferases, such as SUV39H2 and SETDB ${ }^{[25]}$, and are equipotent in effectively reducing H3K9 dimethylation $^{[23]}$. We administered UNC0642 or A-366 to mice either during gestation or in adulthood, mimicking the effects of genetic knockdown of these drug targets at conception or only in the postnatal period. We measured H3K9 dimethylation (H3K9me2) levels, which should be decreased by G9a/ GLP inhibition in adult mice. We also conducted a series of behavioral tests related to anxiety (elevated zero maze, marble burying, novelty-suppressed feeding, and the three-chamber social interaction test) in adult mice. We used two different chemical inhibitors of G9a/GLP to control for possible nonspecific or off-target effects of each compound.

We found that G9a/GLP inhibition during embryonic development increased adult anxiety-like behavior, while adult G9a/GLP inhibition decreased anxiety-like behaviors. Our data provide further evidence that epigenetic factors such as G9a/GLP methyltransferases can contribute to anxiety, and suggest that further study of G9a/GLP could be useful for developing anxiolytic drugs.

\section{Materials and methods Animals}

Wild-type male and female C57BL/6 mice were purchased from Charles River Laboratories, Inc (Toronto, ON, Canada). Male mice were housed in pairs, and female mice were housed in groups of six to ten. All mice were held in a temperature $\left(23 \pm 1{ }^{\circ} \mathrm{C}\right)$ - and humidity-controlled $(50 \% \pm 10 \%)$ room with a 12-h artificial light/dark cycle (lights on at 07:00). Mice had ad libitum access to standard laboratory rodent chow and water. All protocols were approved by the Centre for Addiction and Mental Health (CAMH) Animal Care Committee (protocol numbers 666 and 752).

\section{Drugs and injection schedule}

The effects of both acute and chronic dosing of the two G9a/ GLP inhibitors were assessed. For acute treatment, UNC0642 or A-366 at 1 or $2 \mathrm{mg} / \mathrm{kg}$ or UNC0642 at $4 \mathrm{mg} / \mathrm{kg}$ was administered to male mice by intraperitoneal injection, and behavioral testing was performed $30 \mathrm{~min}$ later. For chronic treatment, the same doses as used for acute treatment were injected daily into male mice for 14 days, and behavioral testing was performed $30 \mathrm{~min}$ after the last injection. Test doses of A-366 at $4 \mathrm{mg} / \mathrm{kg}$ were lethal and therefore were not used for this experiment. For in utero experiments, daily intraperitoneal (ip) injections of UNC0642 at 2 or $4 \mathrm{mg} / \mathrm{kg}$ were administered to pregnant dams, starting at E9.5 and continuing until birth. All injections took place between 10:00 and 16:00. UNC0642

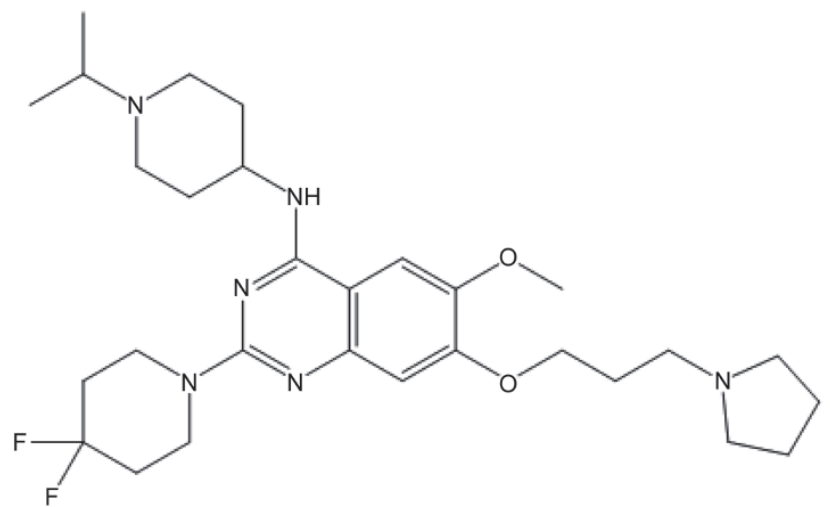

UNC0642

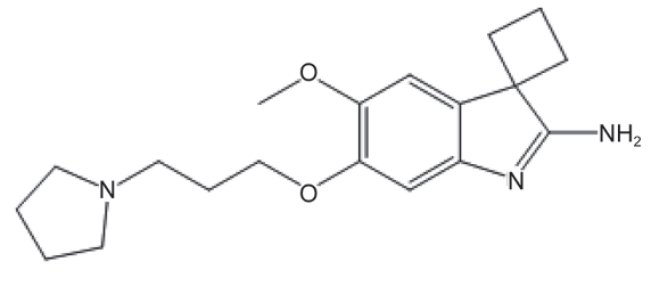

A-366

Figure 1. Chemical structures of UNC0642 and A366. 
and A-366 were dissolved in $0.1 \mathrm{~mol} / \mathrm{L}$ sodium citrate buffer, and the $\mathrm{pH}$ was adjusted to 7.4 with $\mathrm{HCl}$. The vehicle-only control was $0.1 \mathrm{~mol} / \mathrm{L}$ sodium citrate buffer. UNC0642 was a gift from Dr Jian JIN at Mount Sinai Hospital, NY, USA. A-366 was purchased from Tocris (Ontario, Canada). We used diazepam $1 \mathrm{mg} / \mathrm{kg}$ (Sandoz, Canada; $225 \mathrm{mg} / \mathrm{mL}$ in propylene glycol) as the positive control drug treatment for the acute dosing experiment. For the chronic dosing experiment, the common antidepressant venlafaxine at $16 \mathrm{mg} / \mathrm{kg}^{[26,27]}$ (Tocris, Canada; in $0.9 \%$ saline) was used as a positive control.

\section{Behavioral studies}

\section{Elevated zero maze (EZM)}

The elevated zero maze consisted of a 5-cm-wide circular track with an inner diameter of $40 \mathrm{~cm}$. The maze had four quadrants: two opposing open quadrants and two opposing closed quadrants. The closed quadrants had walls $15 \mathrm{~cm}$ high. The maze was elevated $40 \mathrm{~cm}$ above the ground and was illuminated with six, 32-W overhead fluorescent lights (2800 $\mathrm{lm}$ each). The test mouse was placed in an open quadrant facing a closed quadrant and allowed to explore the maze for five minutes. If the mouse fell off the maze, it was immediately put back at the location from which it fell. Each trial was video recorded and analyzed using EthoVision XT software v10 (Noldus Information Technology, the Netherlands). Between trials, the apparatus was cleaned with Virox and $70 \%$ ethanol to sanitize it and remove odor. The time spent in the open areas compared with the closed areas is usually interpreted as an indicator of anxiety-like behavior (more anxious animals spend less time in the open areas).

\section{Marble burying}

A plastic cage, approximately $20 \mathrm{~cm} \times 30 \mathrm{~cm}$, was filled with $5 \mathrm{~cm}$ of corncob bedding, which was lightly pressed down to make a flat, even surface. Twenty glass marbles were evenly spaced in five rows of four on the flat surface. The test animal was placed in the cage for $30 \mathrm{~min}$ and recorded using EthoVision. At the end of the trial, the number of marbles at least two-thirds buried below the corncob bedding was counted.

\section{Novelty-suppressed feeding}

Mice were food deprived for $16 \mathrm{~h}$ prior to the test and weighed before and after testing. On the test day, mice were temporarily transferred to a holding cage. During the test, the mouse was placed in an open field $(40 \mathrm{~cm} \times 40 \mathrm{~cm} \times 40 \mathrm{~cm})$ with a solid floor. A food pellet was placed in the center of the box, and the time for the mouse to begin eating was recorded. If the test mouse did not eat in the open field for $10 \mathrm{~min}$, a latency of $600 \mathrm{~s}$ to eat in the novel environment was recorded. The mouse was then returned to the home cage with a preweighed food pellet and allowed to eat for $5 \mathrm{~min}$, after which the weight of the food pellet was recorded.

\section{Crawley's three-chamber social approach test}

Social interaction was assessed in a rectangular, three-chambered glass box. Each chamber measured $19 \mathrm{~cm} \times 45 \mathrm{~cm}$. Adja- cent chambers were separated by a clear plastic wall with an open door, allowing free movement between chambers. Mice unfamiliar to the test mouse, $i e$, stranger mice, were contained in cylindrical wire cages $(10 \mathrm{~cm} \times 10 \mathrm{~cm})$, with one cage in each side chamber. Mice were habituated to the testing room for one hour before each trial. The trial consisted of three phases: habituation, social affiliation, and social novelty. For the habituation phase, the test animal was allowed to explore the middle chamber for $5 \mathrm{~min}$. For the social affiliation phase, a stranger mouse inside a mesh cage was introduced into one of the side chambers. The movement of the test mouse in all three chambers was recorded for 10 min using EthoVision. For the social novelty phase, another stranger mouse was introduced into the previously vacant side chamber. Again, the activity of the test mouse was recorded as it explored all three chambers. After each trial, the apparatus was cleaned with $70 \%$ ethanol and Virox. All behavioral studies were carried out between 10:00 and 17:00. Flow charts showing the experimental timeline are in Supplementary Figures 1 and 2.

Note that only male mice were examined for the experiments in which adult mice were injected with drugs. For the in utero exposure experiment, we examined both the male and female offspring of pregnant dams injected with UNC0642 or vehicle.

\section{Effect of UNC0642 and A-366 on histone methylation}

Western blots were performed with an SDS-PAGE electrophoresis system as described previously ${ }^{[28]}$. Briefly, mice were killed by cervical dislocation one day after the noveltysuppressed feeding test. The whole brain (excluding the cerebellum and brainstem) was placed in homogenization buffer (50 mmol/L Tris-HCl, pH 7.5, 25 mmol/L KCl, 250 mmol/L sucrose, $2 \mathrm{mmol} / \mathrm{L}$ sodium butyrate, $1 \mathrm{mmol} / \mathrm{L}$ sodium orthovanadate, $0.5 \mathrm{mmol} / \mathrm{L}$ PMSF, $1 \times$ protease inhibitor cocktail) and homogenized. The homogenate was centrifuged at $7700 \times g$ for $1 \mathrm{~min}$ at $4^{\circ} \mathrm{C}$. The pellet (containing the nuclear fraction) was resuspended in $500 \mu \mathrm{L}$ of $0.4 \mathrm{~mol} / \mathrm{L} \mathrm{H}_{2} \mathrm{SO}_{4}$ by thorough trituration, then incubated on ice for $30 \mathrm{~min}$ with intermittent vortexing. Then, these $1.5 \mathrm{~mL}$ tubes were centrifuged at maximum speed for $10 \mathrm{~min}$ at $4^{\circ} \mathrm{C}$. The supernatant was transferred to new tubes, and the histones were precipitated with $250 \mu \mathrm{L}$ of trichloroacetic acid and sodium deoxycholate on ice for $30 \mathrm{~min}$, then centrifuged at maximum speed for $30 \mathrm{~min}$ at $4^{\circ} \mathrm{C}$. The pellet was rinsed with acetone, centrifuged again, and then dried for $5 \mathrm{~min}$. Nuclear histone protein samples were resuspended in $50 \mu \mathrm{L}$ of $10 \mathrm{mmol} / \mathrm{L}$ Tris- $\mathrm{HCl}$ $(\mathrm{pH} 8.0)$ at $6 \mu \mathrm{g} / \mu \mathrm{L}$ and electrophoresed on a $1.5 \mathrm{~mol} / \mathrm{L}$ Tris gel with Tris running buffer. The proteins were transferred to a nitrocellulose membrane and probed either with a primary antibody against all histone 3 proteins (Abcam, Cambridge, UK, ab1791) or with an antibody against the histone 3 protein dimethylated at lysine 9 (H3K9me2; Abcam, ab1220). A horseradish peroxidase-conjugated goat anti-mouse antibody was then added, and secondary antibodies were detected through enhanced chemiluminescence (ECL Plus, General Electric Healthcare, Milwaukee, WI, USA). The total amount of his- 

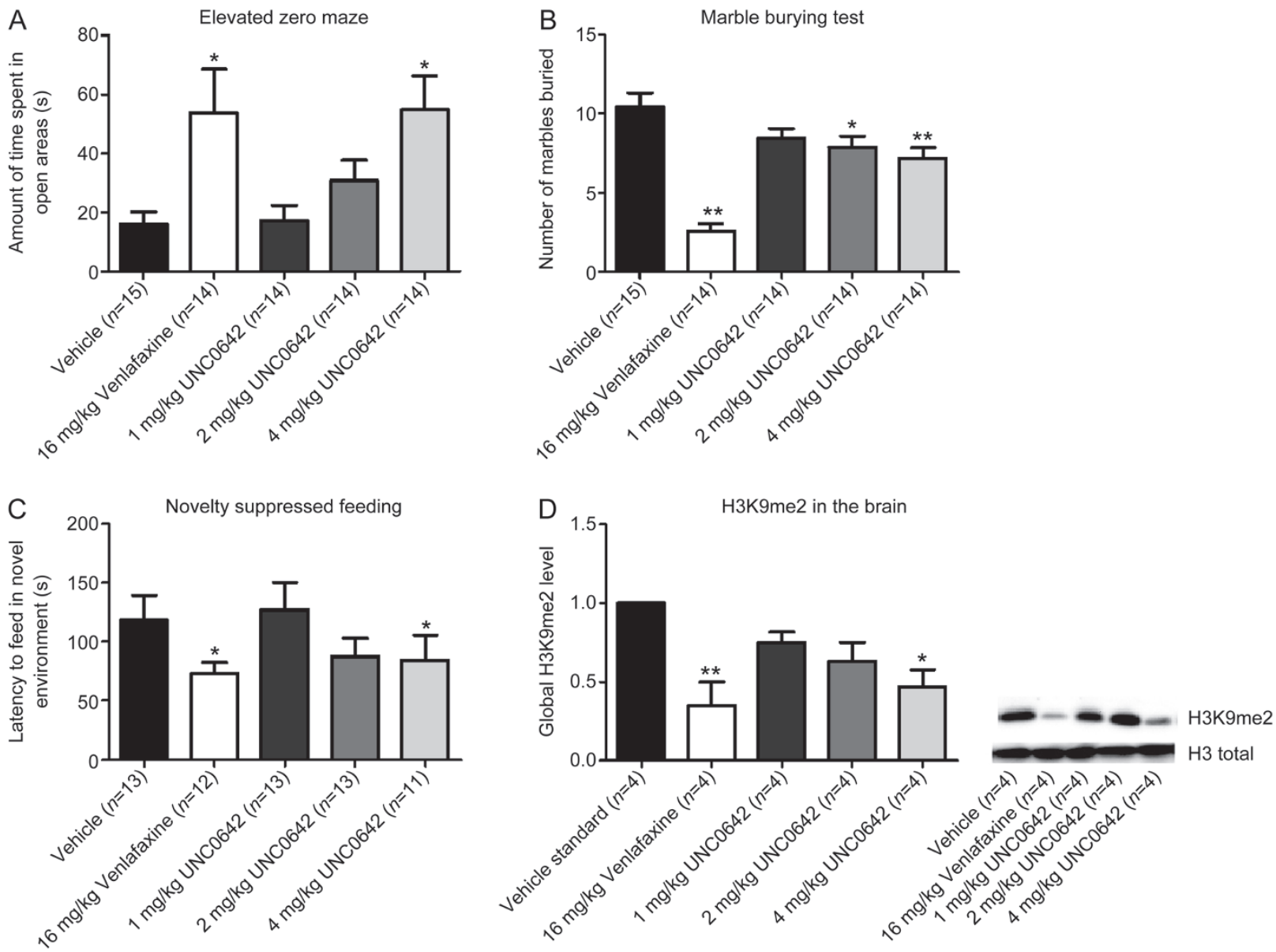

Figure 2. Chronic UNC0642 treatment decreases anxiety-related behaviours in mice. (A) Venlafaxine at $16 \mathrm{mg} / \mathrm{kg}(54 \pm 15 \mathrm{~s}, P=0.017)$ and UNC0642 at $4 \mathrm{mg} / \mathrm{kg}(55 \pm 11 \mathrm{~s}, P=0.017)$ increased the time mice spent in the open areas. (B) Venlafaxine at $16 \mathrm{mg} / \mathrm{kg}(2.57 \pm 0.49, P=0.001), \mathrm{UNC0642}$ at $2 \mathrm{mg} / \mathrm{kg}(7.86 \pm 0.7, P=0.039)$ and $4 \mathrm{mg} / \mathrm{kg}(7.14 \pm 0.69, P=0.005)$ decreased the number of marbles buried in the MBT. (C) Venlafaxine at $16 \mathrm{mg} / \mathrm{kg}$ $(73 \pm 10 \mathrm{~s}, P=0.022)$, and UNC0642 at $4 \mathrm{mg} / \mathrm{kg}(85 \pm 21 \mathrm{~s}, P=0.02)$ decreased the latency to eat. (D) Venlafaxine at $16 \mathrm{mg} / \mathrm{kg}(0.53 \pm 0.14, P=0.009)$ and UNC0642 at $4 \mathrm{mg} / \mathrm{kg}(0.49 \pm 0.12, P=0.005)$ decreased H3K9me2 levels. ${ }^{*} P<0.05,{ }^{* *} P<0.01$.

tone 3 protein was used as the loading control. The amount of $\mathrm{H} 3 \mathrm{~K} 9 \mathrm{me} 2$ protein relative to total histone 3 protein was calculated and compared between treatment groups. Each group was normalized to the control group, which was assigned a value of 1 .

\section{Statistical analysis}

All data were analyzed using SPSS 21.0 (IBM). All behavioral data were tested for normality using the Shapiro-Wilk test. One-way ANOVA was used to analyze the results with a 2-tailed Dunnett's post hoc test, which accounts for multiple comparisons. When the data were not normally distributed, we used the Kruskal-Wallis test followed by Dunn's post hoc test. Post hoc comparisons between active treatment groups relied on Tukey's test. For the automated three-chamber social approach test, repeated measures ANOVA was used to compare time spent in the two side chambers, with the factor of drug treatment $(0.1 \mathrm{~mol} / \mathrm{L}$ sodium citrate buffer vehicle, 2 $\mathrm{mg} / \mathrm{kg}$ UNC0642 or $4 \mathrm{mg} / \mathrm{kg}$ UNC0642). Otherwise, all data are expressed as the mean \pm standard error of the mean (SEM).

\section{Results}

Chronic UNC0642 and A-366 treatment decreased anxiety-like behaviors and reduced brain $\mathrm{H} 3 \mathrm{~K} 9 \mathrm{me} 2$ levels

We examined the anxiolytic-like effects of G9a/GLP inhibition in adult male mice treated chronically for 14 days with UNC0642. One-way ANOVA showed that UNC0642 caused a dose-dependent increase in the time spent in the open areas of the elevated zero maze $\left(F_{4,66}=4.2, P=0.004\right.$; Figure $\left.2 \mathrm{~A}\right)$, which is usually considered an anxiolytic-like effect. The positive control drug venlafaxine at $16 \mathrm{mg} / \mathrm{kg}$ also increased the time mice spent in the open areas ( $54 \pm 15 \mathrm{~s})$, similar to UNC0642 at 4 $\mathrm{mg} / \mathrm{kg}(55 \pm 11 \mathrm{~s}$; Tukey's test $P=1.0)$, and both of those groups spent significantly longer than the vehicle control group (16 \pm 4 s; Dunnett's post hoc test, $P=0.017$ for both comparisons). At lower doses, the UNC0642 group showed a consistent trend towards more time in the open arms compared to the vehicle group, but the trend did not reach statistical significance (Dunnett's post hoc test, $17 \pm 5 \mathrm{~s}$ at $1 \mathrm{mg} / \mathrm{kg}, P=1.0 ; 31 \pm 7 \mathrm{~s}$ at $2 \mathrm{mg} / \mathrm{kg}$, $P=0.62)$.

Chronic UNC0642 at 2 or $4 \mathrm{mg} / \mathrm{kg}$ also significantly decreased 
the number of marbles buried $\left(F_{4,66}=17.36, P<0.0001\right.$; Figure 2B). Additionally, UNC0642 caused a dose-dependent decrease in the latency to feed in the novelty-suppressed feeding test (Kruskal-Wallis test $X^{2}(4)=10.94, P=0.027$; Figure 2C). In comparison to the vehicle control (119 $\pm 20 \mathrm{~s}), \mathrm{UNC} 0642$ at $4 \mathrm{mg} /$ $\mathrm{kg}(85 \pm 21 \mathrm{~s}$, Dunn's post hoc test, $P=0.02)$ had similar effects to venlafaxine at $16 \mathrm{mg} / \mathrm{kg}(73 \pm 10 \mathrm{~s}$, Dunn's post hoc test, $P=0.022)$ on novelty-suppressed feeding. The behavioral effects of A-366 treatment were similar to those of UNC0642. Chronic treatment of male mice with A-366 at $2 \mathrm{mg} / \mathrm{kg}$ significantly increased the amount of time spent in the open areas in the elevated zero maze $\left(F_{3,50}=7.25, P=0.0004\right)$, decreased the number of marbles buried in the marble-burying test $\left(F_{3,50}=13.83, P=0.000001\right)$, and decreased latency to feed in the novelty-suppressed feeding test $\left(F_{3,48}=7.2\right.$, $P=0.0004$; Figure $3 \mathrm{~A}-\mathrm{C})$. Neither UNC0642 nor A-366 altered the total distance travelled within the zero maze (Supplementary Figure $3 \mathrm{~A}-\mathrm{D})$, suggesting that the compounds did not impair motor function or cause sedation such that the animal did not move as much overall.
If UNC0642 and A-366 effectively inhibited G9a/GLP in the brain, histone 3 dimethylation at lysine 9 (H3K9me2) should be reduced. Thus, we measured H3K9me2 using Western blots. Chronic UNC0642 $(4 \mathrm{mg} / \mathrm{kg})$ treatment significantly reduced $\mathrm{H} 3 \mathrm{~K} 9 \mathrm{me} 2$ levels compared with the vehicle control (ratios between $\mathrm{H} 3 \mathrm{~K} 9 \mathrm{me} 2$ and total $\mathrm{H} 3$ for treated animals= $0.47 \pm 0.11$; controls $=1.0$; one-way ANOVA $F_{4,11}=4.52, P=0.03$; Figure 2d). Chronic A-366 (2 mg/ kg) treatment had similar effects (ratios between $\mathrm{H} 3 \mathrm{~K} 9 \mathrm{me} 2$ and total $\mathrm{H} 3$ for treated= $0.37 \pm 0.11$ vs control: $1.0 ; F_{3,13}=3.8, P=0.037$; Figure $3 \mathrm{~d}$ ). Venlafaxine also significantly decreased global brain H3K9me2 levels at $16 \mathrm{mg} / \mathrm{kg}(0.53 \pm 0.14$ compared with the control condition, which was set at $1.0(P=0.009)$ in $\mathrm{UNC} 0642$ experiments; $0.46 \pm 0.045$ compared with the control value of $1.0(P=0.039)$ in A-366 experiments; Figures 2D and 3D).

In contrast to the effects of chronic UNC0642 or A-366 administration, a single dose of either UNC0642 or A-366 did not alter the time spent in the open areas of the elevated zero maze (Figure 4).
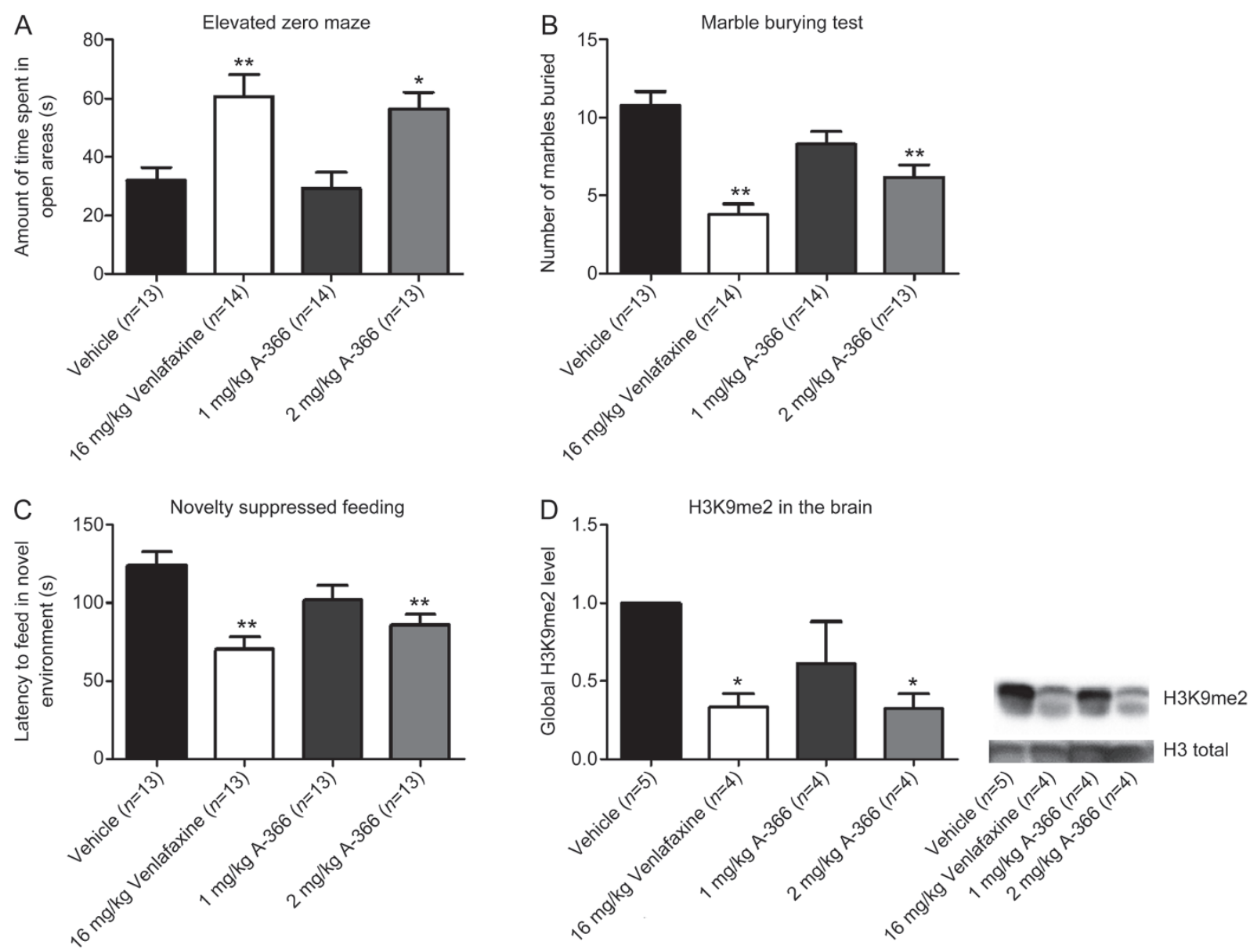

Figure 3. Chronic A-366 treatment decreases anxiety-related behaviours in mice. All tests were performed after 14 days of ip injection of venlafaxine at $16 \mathrm{mg} / \mathrm{kg}$ or A-366 at 1 or $2 \mathrm{mg} / \mathrm{kg}$ in male mice. (A) Venlafaxine at $16 \mathrm{mg} / \mathrm{kg}(61 \pm 8 \mathrm{~s}, P=0.004)$ and A-366 at $2 \mathrm{mg} / \mathrm{kg}(56 \pm 6 \mathrm{~s}, P=0.029)$ increased the time mice spent in open areas. (B) Venlafaxine at $16 \mathrm{mg} / \mathrm{kg}(3.79 \pm 0.67, P=0.000000018)$, and $\mathrm{A}-366$ at $2 \mathrm{mg} / \mathrm{kg}(6.15 \pm 0.82, P=0.001)$ decreased the number of marbles buried in the MBT. (C) Venlafaxine at $16 \mathrm{mg} / \mathrm{kg}(70 \pm 8 \mathrm{~s}, P=0.00005)$ and A-366 at $2 \mathrm{mg} / \mathrm{kg}(86 \pm 7 \mathrm{~s}, P=0.009) \mathrm{decreased}$ the latency to feed in the novel environment. (D) Venlafaxine at $16 \mathrm{mg} / \mathrm{kg}(0.33 \pm 0.09, P=0.039)$ and $\mathrm{A}-366$ at $2 \mathrm{mg} / \mathrm{kg}(0.32 \pm 0.10, P=0.036)$ decreased H3K9me2 levels. ${ }^{*} P<0.05,{ }^{* *} P<0.01$. 

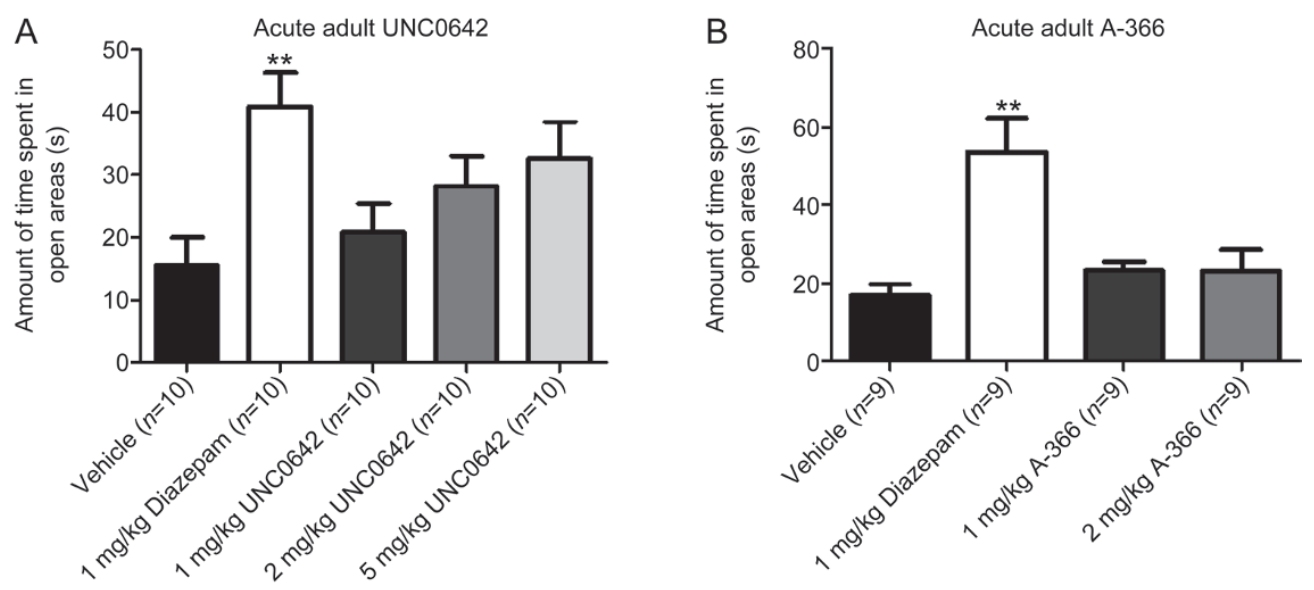

Figure 4. Acute UNC0642 and A-366 treatment did not affect anxiety-related behaviours in mice. All tests were performed 30 min after ip injection of diazepam at $1 \mathrm{mg} / \mathrm{kg}$, UNC0642/A-366 at 1 or $2 \mathrm{mg} / \mathrm{kg}$, or UNC0642 at $5 \mathrm{mg} / \mathrm{kg}$ in male mice. (A) Diazepam at $1 \mathrm{mg} / \mathrm{kg}(41 \pm 5 \mathrm{~s}, P=0.003)$ increased the time mice spent in open areas. (B) Diazepam at $1 \mathrm{mg} / \mathrm{kg}(54 \pm 9, P=0.00138)$ increased the time mice spent in open areas. ${ }^{* *} P<0.01$.

In utero exposure to UNC0642 decreased social interaction and increased anxiety-related behavior in adult mice

To investigate the effect of G9a/GLP during early brain development on anxiety and social behaviors, we used UNC0642 to inhibit G9a/GLP in utero. We administered UNC0642 (2 $\mathrm{mg} / \mathrm{kg}$ or $4 \mathrm{mg} / \mathrm{kg}$, ip daily) to pregnant mice from E9.5 until birth. Behavioral testing was performed when both male and female offspring reached 8 weeks of age. One-way ANOVA showed a significant main effect of in utero exposure to UNC0642 $\left(F_{2,19}=4.90, P=0.019\right)$ on time spent in the open areas of the elevated zero maze. In utero exposure to UNC0642 at 4 $\mathrm{mg} / \mathrm{kg}$ significantly decreased time spent in open areas of the elevated zero maze in comparison to the vehicle control $(4 \pm 1$ s vs $25 \pm 4$ s Dunnett's post hoc test $P=0.026$; Figure $5 \mathrm{~A})$. A oneway ANOVA revealed a significant effect of drug treatment in the marble-burying test $\left(F_{2,23}=10.65, P=0.0005\right)$. UNC0642 at $2 \mathrm{mg} / \mathrm{kg}$ or $4 \mathrm{mg} / \mathrm{kg}$ increased the number of marbles buried compared with the control $(6.43 \pm 0.69$ and $5.43 \pm 1.25$ vs $2.0 \pm 0.44, P=0.001$ and $P=0.006$, for doses of $2 \mathrm{mg} / \mathrm{kg}$ and $4 \mathrm{mg} / \mathrm{kg}$, respectively; Figure 5B). All treatment groups had similar levels of overall movement in the elevated zero maze (Supplementary Figure 1E-F). In utero UNC0642 exposure caused a reduction in the time spent with an unfamiliar mouse in Crawley's three-chamber social interaction test (Figure 5C), but there was no effect on response to social novelty (data not shown). There was no change in adult brain H3K9me2 levels with UNC0642 exposure during gestation $\left(F_{2,10}=0.7828\right.$, $P=0.48$; Figure 5D). We found no significant effect of sex and no significant interaction between sex and treatment group on behavior or histone methylation.

\section{Discussion}

In summary, we found that chronic pharmacological inhibition of G9a/GLP in adult mice reduces anxiety-like behaviors. The results of adult G9a/GLP inhibition are consistent with the anti-anxiety effects of several medications that also inhibit G9a/GLP and with the decreased anxiety-like behavior seen in mice with postnatal knockout of G9a ${ }^{[21]}$. Thus, our results provide additional evidence that suppressing G9a/GLP activity in adulthood is anxiolytic and suggests that this may be one mechanism by which existing anti-anxiety medications work.

We chose to test two different chemical inhibitors of G9a/ GLP in order to control for potential non-specific effects of each drug. Although UNC0642 is highly specific in inhibiting G9a/GLP as opposed to a variety of epigenetic and nonepigenetic targets, there is still a possibility that some of the observed effects could be due to off-target binding (i.e., not due to G9a/GLP inhibition). Our behavioral findings were reproducible with A-366, which suggests that these effects are due to G9a/GLP inhibition rather than off-target activity.

Venlafaxine was chosen as our positive control for chronic drug treatment because of its clinical use in humans as a longterm treatment for anxiety, and because previous animal studies have reported strong effects in the behavioral tests we used $^{[26,27]}$. We found that venlafaxine also decreased H3K9me2 levels in the mouse brain, consistent with the other antidepressant medications previously shown to inhibit G9a ${ }^{[19]}$. The observed decrease in histone H3K9 methylation by venlafaxine further supports the notion that decreased $\mathrm{H} 3 \mathrm{~K} 9 \mathrm{me} 2$ levels play a role in reducing anxiety-related behaviors.

Another clinical implication of our study is that G9a/GLP could be explored as a treatment target for developing new medications to treat anxiety disorders. However, alterations to the dynamic process of histone modification have the potential to affect all tissues, not just the brain. In fact, mitotically active cells and tissues can be especially vulnerable to disruptions in epigenetic regulation, and this is exploited by anti-cancer drugs that target the epigenetic machinery, including histone methyltransferases ${ }^{[29]}$. Thus, while a highly selective compound targeting G9a/GLP in the brain may be effective for treating psychiatric symptoms, there may also be the problem of systemic toxicity. Further investigation of the downstream effects of G9a/GLP inhibition and H3K9 demethylation could 

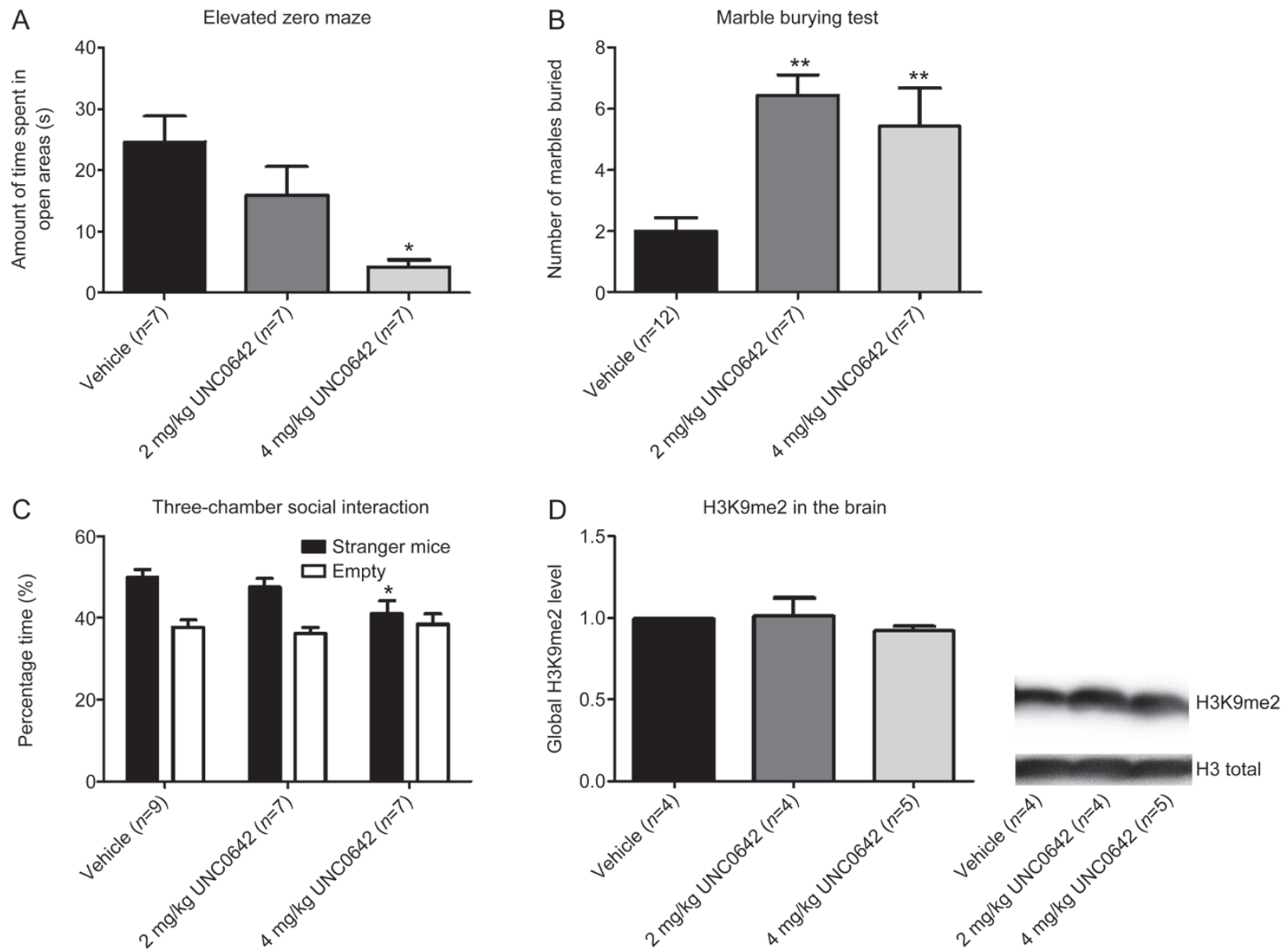

Figure 5. In utero exposure to UNC0642 increased anxiety-related behaviours and decreased social interaction in adult mice. I.p. injection of UNC0642 at $2 \mathrm{mg} / \mathrm{kg}$ or $4 \mathrm{mg} / \mathrm{kg}$ started on $\mathrm{E9} .5$ and continued until the pups were born. All tests were performed after the pups had matured to eight weeks of age. (A) UNC0642 at $4 \mathrm{mg} / \mathrm{kg}(4 \pm 1 \mathrm{~s}, P=0.026)$ decreased the time mice spent in the open areas. There were seven mice (four males) in each treatment group. (B) UNC0642 at $2 \mathrm{mg} / \mathrm{kg}(6.43 \pm 0.69, P=0.001)$ and UNC0642 at $4 \mathrm{mg} / \mathrm{kg}(5.43 \pm 1.25, P=0.006)$ increased the number of marbles buried. There were twelve (six males), seven (four males), and seven (four males) mice in the vehicle, UNC0642 at $2 \mathrm{mg} / \mathrm{kg}$ and UNC0642 at $4 \mathrm{mg} / \mathrm{kg}$ groups, respectively. (C) UNC0642 at $4 \mathrm{mg} / \mathrm{kg}(41 \% \pm 3 \%, P=0.001)$ decreased the time spent with the unfamiliar mouse. There were nine (four males), seven (four males), and seven (four males) mice in the vehicle, UNC0642 at $2 \mathrm{mg} / \mathrm{kg}$ and UNC0642 at $4 \mathrm{mg} / \mathrm{kg}$ groups, respectively. (D) H3K9me2 levels were measured with Western blot, and normalized to total histone 3 levels. One way ANOVA did not reveal a significant effect of drug treatment $\left(F_{2,10}=0.78, P=0.48\right)$. There were four (two males), four (two males), and five (two males) mice in the vehicle, UNC0642 at $2 \mathrm{mg} / \mathrm{kg}$ and UNC0642 at 4 $\mathrm{mg} / \mathrm{kg}$ groups, respectively. ${ }^{*} P<0.05,{ }^{* *} P<0.01$.

point towards novel treatment targets that could have less severe systemic effects than G9a/GLP inhibition.

In contrast to the effects of adult G9a/GLP inhibition, administering UNC0642 to mice in utero, during the second half of gestation, has the opposite effect, resulting in increased anxiety-related behaviors and decreased social interaction in adulthood. Our results are consistent with the abnormal autistic-like social behavior seen in humans with mutations in the GLP (EHMT1) gene as part of Kleefstra syndrome, as well as the increased anxiety-like behavior and deficits in social interaction in mice with GLP haplodeficiency ${ }^{[30]}$. UNC0642 administration to the pregnant dams from E9.5 to birth did not alter global H3K9me2 levels in the brains of the offspring as adults, in contrast to chronic adult G9a/GLP inhibition, which reduced $\mathrm{H} 3 \mathrm{~K} 9 \mathrm{me} 2$ levels. We speculate that G9a/GLP inhibi- tion reduced $\mathrm{H} 3 \mathrm{~K} 9$ methylation during the second half of gestation, thereby altering neurodevelopment and adult behavior, although we did not directly test this hypothesis. Although H3K9 methylation was at normal levels in adulthood, G9a/ GLP inhibition during gestation could have affected brain development through several pathways. For example, G9a/ GLP interacts with polycomb repressive complex 2 (PRC2) in a cooperative fashion to maintain silencing of a subset of developmental genes, particularly those involved in neuronal differentiation $^{[31]}$. There is also evidence implicating G9a in regulating other neural functions such as cocaine-induced plasticity ${ }^{[32]}$; therefore, it is plausible that inhibiting G9a during embryonic brain development could have lasting effects on anxiety-related behaviors. However, since we did not directly measure H3K9me2 in the embryonic brain, we cannot be cer- 
tain that the behavioral changes observed were due to G9a/ GLP inhibition. It is possible that UNC0642 did not penetrate adequately into the embryonic brain after administration to the pregnant dam and that the behavioral changes in adult offspring are due to maternal effects or other non-specific effects of UNC0642 on the developing embryo.

An important clinical implication of these data is that during pregnancy, treatment with medications that inhibit G9a/ GLP, including venlafaxine, may affect anxiety and could contribute to anxiety disorders in the offspring. This observation requires further careful experimentation, but given that amitriptyline, imipramine, and paroxetine also inhibit G9a/GLP, there is reason to investigate the potential for adverse consequences arising from gestational exposure to these common antidepressant medications. Others have also found evidence that perinatal exposure to fluoxetine, another antidepressant, can increase anxiety-related behaviors later in life ${ }^{[33]}$.

In summary, we show that G9a/GLP inhibition with the drugs UNC0642 and A-366 has anxiolytic-like effects in mice. In contrast, giving a G9a/GLP inhibitor to pregnant dams produces increased anxiety and decreased social interaction in the offspring later in life, consistent with the effects of GLP genetic knockout studies published previously. Our results suggest that targeting the G9a/GLP pathway could be a novel strategy for developing new medications to treat anxiety. The effects of UNC0642 exposure during early development demonstrate that these epigenetic enzymes are important in the origin of anxiety-related behaviors, and further research into this area is warranted, especially with regard to the fetal effects of common antidepressants prescribed to pregnant patients.

\section{Author contribution}

Dong-yao WANG designed and performed experiments, analyzed data and wrote the paper; Joel KOSOWAN performed experiments and analyzed data; James SAMSOM, Laura LEUNG, Kai-lai ZHANG, Ying-xiang LI performed experiments; Yan XIONG created and contributed chemical compounds; Jian JIN created and contributed a chemical compound; Arturas PETRONIS conceived the study, designed experiments and edited the paper; Gabriel $\mathrm{OH}$ edited the paper; Albert H C WONG designed experiments and wrote the paper.

\section{Supplementary information}

Supplementary information is available at the website of Acta Pharmacologica Sinica.

\section{References}

1 Pelissolo A, Andre C, Chignon JM, Dutoit D, Martin P, Richard-Berthe $\mathrm{C}$, et al. Anxiety disorders in private practice psychiatric out-patients: prevalence, comorbidity and burden (DELTA study). Encephale 2001; 28: 510-9.

2 Üstün TB, Ayuso-Mateos JL, Chatterji S, Mathers C, Murray CJ. Global burden of depressive disorders in the year 2000. Br J Psychiatry 2004; 184: 386-92

3 Onyett SR. The benzodiazepine withdrawal syndrome and its management. J R Coll Gen Pract 1989; 39: 160-3.

4 Stein DJ, Ipser JC, Seedat S. Pharmacotherapy for post traumatic stress disorder (PTSD). Cochrane Database Syst Rev 2006: CD002795.

5 Kapczinski F, Lima MS, Souza JS, Schmitt R. Antidepressants for generalized anxiety disorder. Cochrane Database Syst Rev 2003: CD003592.

6 Tsankova N, Renthal W, Kumar A, Nestler EJ. Epigenetic regulation in psychiatric disorders. Nat Rev Neurosci 2007; 8: 355-67.

7 Sun H, Kennedy PJ, Nestler EJ. Epigenetics of the depressed brain: role of histone acetylation and methylation. Neuropsychopharmacology 2013; 38: 124-37.

8 Klengel T, Mehta D, Anacker C, Rex-Haffner M, Pruessner JC, Pariante $\mathrm{CM}$, et al. Allele-specific FKBP5 DNA demethylation mediates genechildhood trauma interactions. Nat Neurosci 2013; 16: 33-41.

9 McGowan PO, Sasaki A, D'Alessio AC, Dymov S, Labonté B, Szyf M, et al. Epigenetic regulation of the glucocorticoid receptor in human brain associates with childhood abuse. Nat Neurosci 2009; 12: 3428.

10 Fischer A, Sananbenesi F, Wang X, Dobbin M, Tsai LH. Recovery of learning and memory is associated with chromatin remodelling. Nature 2007; 447: 178-82.

11 Kilgore M, Miller CA, Fass DM, Hennig KM, Haggarty SJ, Sweatt JD, et al. Inhibitors of class 1 histone deacetylases reverse contextual memory deficits in a mouse model of Alzheimer's disease. Neuropsychopharmacology 2010; 35: 870-80.

12 Qing H, He G, Ly PTT, Fox CJ, Staufenbiel M, Cai F, et al. Valproic acid inhibits Abeta production, neuritic plaque formation, and behavioral deficits in Alzheimer's disease mouse models. J Exp Med 2008; 205 : 2781-9.

13 Kurita M, Holloway T, García-Bea A, Kozlenkov A, Friedman AK, Moreno $\mathrm{JL}$, et al. HDAC2 regulates atypical antipsychotic responses through the modulation of mGlu2 promoter activity. Nat Neurosci 2012; 15: 1245-54.

14 Tsankova NM, Berton O, Renthal W, Kumar A, Neve RL, Nestler EJ. Sustained hippocampal chromatin regulation in a mouse model of depression and antidepressant action. Nat Neurosci 2006; 9: 51925.

15 Krishnan V, Nestler EJ. The molecular neurobiology of depression. Nature 2008; 455: 894-902.

16 Covington HE, 3rd, Maze I, LaPlant QC, Vialou VF, Ohnishi YN, Berton 0 , et al. Antidepressant actions of histone deacetylase inhibitors. J Neurosci 2009; 29: 11451-60.

17 The UKECTRG. Efficacy and safety of electroconvulsive therapy in depressive disorders: a systematic review and meta-analysis. Lancet 2003; 361: 799-808.

18 Tsankova NM, Kumar A, Nestler EJ. Histone modifications at gene promoter regions in rat hippocampus after acute and chronic electroconvulsive seizures. J Neurosci 2004; 24: 5603-10.

19 Zimmermann N, Zschocke J, Perisic T, Yu S, Holsboer F, Rein T. Antidepressants inhibit DNA methyltransferase 1 through reducing G9a levels. Biochem J 2012; 448: 93-102.

20 Shankar SR, Bahirvani AG, Rao VK, Bharathy N, Ow JR, Taneja R. G9a, a multipotent regulator of gene expression. Epigenetics 2013; 8: 16-22.

21 Schaefer A, Sampath SC, Intrator A, Min A, Gertler TS, Surmeier DJ, et al. Control of cognition and adaptive behavior by the GLP/G9a epigenetic suppressor complex. Neuron 2009; 64: 678-91.

22 Willemsen MH, Vulto-van Silfhout AT, Nillesen WM, Wissink-Lindhout WM, van Bokhoven $\mathrm{H}$, Philip N, et al. Update on Kleefstra syndrome. Mol Syndromol 2012; 2: 202-12. 
23 Liu F, Barsyte-Lovejoy D, Li F, Xiong Y, Korboukh V, Huang XP, et al. Discovery of an in vivo chemical probe of the lysine methyltransferases G9a and GLP. J Med Chem 2013; 56: 8931-42.

24 Sweis RF, Pliushchev M, Brown PJ, Guo J, Li F, Maag D, et al. Discovery and development of potent and selective inhibitors of histone methyltransferase G9a. ACS Med Chem Lett 2014; 5: 205-9.

25 Vedadi M, Barsyte-Lovejoy D, Liu F, Rival-Gervier S, Allali-Hassani A, Labrie V, et al. A chemical probe selectively inhibits G9a and GLP methyltransferase activity in cells. Nat Chem Biol 2011; 7: 566-74.

26 Thase ME. Treatment of anxiety disorders with venlafaxine XR. Expert Rev Neurother 2006; 6: 269-82.

27 Dhir A, Kulkarni SK. Venlafaxine reverses chronic fatigue-induced behavioral, biochemical and neurochemical alterations in mice. Pharmacol Biochem Behav 2008; 89: 563-71.

28 Rumbaugh G, Miller CA. Epigenetic changes in the brain: measuring global histone modifications. Methods Mol Biol 2011; 670: 263-74.

29 Zagni C, Chiacchio U, Rescifina A. Histone methyltransferase inhibitors: novel epigenetic agents for cancer treatment. Curr Med Chem 2013; 20: 167-85.

30 Balemans MC, Huibers MM, Eikelenboom NW, Kuipers AJ, van Summeren RC, Pijpers MM, et al. Reduced exploration, increased anxiety, and altered social behavior: autistic-like features of euchromatin histone methyltransferase 1 heterozygous knockout mice. Behav Brain Res 2010; 208: 47-55.

31 Mozzetta C, Pontis J, Fritsch L, Robin P, Portoso M, Proux C, et al. The histone $\mathrm{H} 3$ lysine 9 methyltransferases G9a and GLP regulate polycomb repressive complex 2-mediated gene silencing. Mol Cell 2014; 53: 277-89.

32 Maze I, Covington HE 3rd, Dietz DM, LaPlant Q, Renthal W, Russo SJ, et al. Essential role of the histone methyltransferase G9a in cocaineinduced plasticity. Science 2010; 327: 213-6.

33 Altieri SC, Yang H, O'Brien HJ, Redwine HM, Senturk D, Hensler JG, et al. Perinatal vs genetic programming of serotonin states associated with anxiety. Neuropsychopharmacology 2015; 40: 1456-70. 